
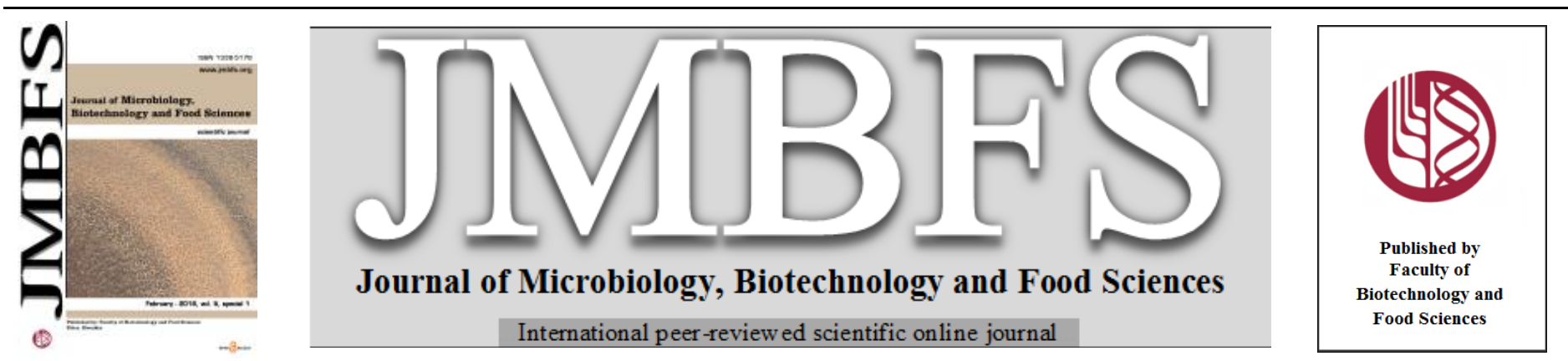

\title{
ENERGETIC PROFILE OF RABBITS AFTER AMYGDALIN ADMINISTRATION
}

\section{Eva Tušimová ${ }^{*}$, Anton Kováčik ${ }^{2}$, Marek Halenár ${ }^{2}$, Katarína Zbyňovská2, L’ubica Chrastinová ${ }^{3}$, Lubomír Ondruška ${ }^{3}$, Rastislav Jurč́ $^{3}$, Eduard Kolesár ${ }^{2}$, Adriana Kolesárováa ${ }^{2}$}

\author{
Address(es): Eva Tušimová, MSc., $\mathrm{PhD}$. \\ ${ }^{1}$ Research Centre AgroBioTech, Slovak University of Agriculture in Nitra, Tr. A. Hlinku 2, 94976 Nitra, Slovak Republic; \\ ${ }^{2}$ Faculty of Biotechnology and Food Sciences, Slovak University of Agriculture in Nitra, Tr. A. Hlinku 2, 94976 Nitra, Slovak Republic; \\ ${ }^{3}$ Animal Production Research Centre Nitra, National Agricultural and Food Center, Hlohovecká 2, 95141 Lužianky, Slovak Republic.
}

*Corresponding author: tusimova.eva@gmail.com

doi: 10.15414/jmbfs.2016.5.special1.50-52

\section{ARTICLE INFO}

Received 16. 12. 2015

Revised 6. 1. 2016

Accepted 21. 1. 2016

Published 8. 2. 2016

Regular article

open 2 access

\begin{abstract}
Amygdalin is a cyanogenic glucoside initially obtained from the seeds of bitter almonds (Prunus dulcis). It is a natural product that owns antitumor activity and has also been used for the treatment of asthma, bronchitis, emphysema, leprosy and diabetes. It is composed of one molecule of benzaldehyde, two molecules of glucose and one molecule of hydrocyanic acid. Cyanide is not cancerocidal as long as glucose is available. The present in vivo study was designed to reveal whether amygdalin is able to cause changes in the energetic profile of rabbit as a biological model. A 12 adult male rabbits were randomly divided into three groups: the control group without any amygdalin administration and two experimental groups receiving daily intramuscular injections (IM) of amygdalin at 0.6 and $3.0 \mathrm{mg} / \mathrm{kg}$ b.w. respectively over the period of 28 days. The body weight of each experimental animal was recorded weekly during the whole study. Serum levels of energetic profile (glucose, triglycerides and cholesterol) were determined. Intramuscular application of amygdalin did not affect $(P \geq 0.05)$ the serum levels of none of selected biochemical parameters significantly. In this in vivo study, no obvious beneficial or negative effects of amygdalin on energetic profile of male rabbits were demonstrated.
\end{abstract}

Keywords: Amygdalin, rabbits, glucose, triglycerides, cholesterol

\section{INTRODUCTION}

Alternative cancer therapy represents a variety of treatments used by cancer patients for cancer prevention, treatment or management of symptoms caused by the malignancy or cancer therapies (Balmer, 1998). Amygdalin is a cyanogenic glucoside initially obtained from the seeds of bitter almonds (Prunus dulcis) (Chwalek and Plé, 2004). It is a major component of the seeds of prunasin family plants, such as apricots, almonds, peaches, apples, and other rosaceous plants (Fukuda et al., 2003). Amygdalin, when pure, is almost entirely harmless (Sollmann, 1949).

Amygdalin (D-mandelonitrile- $\beta$-D-gentiobioside), $\mathrm{C}_{20} \mathrm{H}_{27} \mathrm{NO}_{11}$, is composed of one molecule of benzaldehyde, two molecules of glucose and one molecule of hydrocyanic acid, which is an anti-neoplastic compound (Chang et al., 2006).

Amygdalin is a natural product that owns antitumor activity, less side effects and relatively low priced (Song and $\mathbf{X u}, \mathbf{2 0 1 4}$ ). Besides the antitumor activity, amygdalin has also been used for the treatment of asthma, bronchitis, emphysema, leprosy and diabetes (Zhou et al., 2012). It is also decomposed by the action of $\beta$-D-glucosidase to yield hydrocyanic acid which stimulates the respiratory center reflexively and produces a kind of antitussive and antiasthmatic effects (Badr and Tawfik, 2010; Lv et al., 2005).

As reported by Levi et al. (1965) cyanide is not cancerocidal as long as glucose is available. Therefore it is obvious, the energy profile of patients plays important role in clinical research of amygdalin effect.

The present in vivo study was designed to reveal whether amygdalin is able to cause changes in the energetic profile of rabbit as a biological model.

\section{MATERIAL AND METHODS}

\section{Chemicals}

Amygdalin from apricot kernels ( $\geq 99 \%$ purity) was purchased from SigmaAldrich (St. Louis, MO, USA). Amygdalin was freshly dissolved in sterile saline and $0.5 \mathrm{ml}$ were applied intramuscularly (IM) to musculus biceps femoris on a daily basis.

\section{Animals}

Meat line P91 Californian rabbit males $(\mathrm{n}=12)$ from the experimental farm of the Animal Production Research Centre Nitra (Slovak Republic) were used in the experiments. The rabbits were 150 days old, weighing $4.00 \pm 0.5 \mathrm{~kg}$, and were housed in individual flat-deck wire cages under a constant photoperiod of $12 \mathrm{~h}$ of daylight, temperature $20-24{ }^{\circ} \mathrm{C}$ and humidity $55 \% \pm 10 \%$. The rabbits were fed a standard commercially available feed based on a pelleted concentrate. Animals had free access to feed and water during the study period and no toxic or side effects or death were observed throughout the study. The animals were randomly divided into the three groups, leading to 4 male rabbits in each group. The control group received no amygdalin while the two experimental groups P1 and P2 received a daily intramuscular injection of amygdalin at a dose 0.6 and $3.0 \mathrm{mg} / \mathrm{kg}$ b.w. respectively during 28 days. The body weight of each experimental animal was recorded weekly during the whole study. Institutional and national guidelines for the care and use of animals were followed appropriately, and all experimental procedures were approved by the State Veterinary and Food Institute of Slovak Republic, no. 3398/11-221/3 and Ethic Committee.

\section{Blood Sample Collection.}

During the experiment, three blood collections were carried out (at the beginning of the experiment 0 ; after 14 days and 28 days) to control the health of animals. Venous blood from vena auricularis was collected into tubes. Blood serum was separated from whole blood by centrifugation at $3000 \mathrm{rpm}$ for $10 \mathrm{~min}$. at $20^{\circ} \mathrm{C}$. The clear supernatant (serum) was then separated from the pellet and kept frozen until analysis.

\section{Analysis}

Quantification of glucose, triglycerides and cholesterol after amygdalin supplementation was performed using photometry. Analyses were provided in biochemical and hematological laboratory at the Department of Animal Physiology of SUA through commercial sets DiaSys (Diagnostic Systems GmbH, Germany) on device Rx Monza (Randox Laboratories Ltd., United Kingdom). 
Intra-assay, inter-assay coefficients and sensitiveness for selected parameters are shown in Table 1.

Table 1 Intra-assay, inter-assay coefficients and sensitivity for selected parameters

\begin{tabular}{lccc}
\hline Parameter & $\begin{array}{c}\text { Intra-assay } \\
\text { coefficient (\%) }\end{array}$ & $\begin{array}{c}\text { Inter-assay } \\
\text { coefficient (\%) }\end{array}$ & Sensitivity \\
\hline Glucose & $\leq 1.05$ & $\leq 3.8$ & $0.22 \mathrm{mmol}^{-1}$ \\
\hline Triglycerides & $\leq 1.6$ & $\leq 1.23$ & $0.01 \mathrm{mmol} \mathrm{I}^{-1}$ \\
\hline Cholesterol & $\leq 0.95$ & $\leq 1.09$ & $0.08 \mathrm{mmol} . \mathrm{l}^{-1}$ \\
\hline
\end{tabular}

\section{Statistical analysis}

The significance of differences between the control and experimental groups was evaluated by one-way analysis of variance (ANOVA), with the Dunnett's multiple comparison test using statistical software GraphPad Prism 3.01 (GraphPad Software Inc., San Diego, CA, USA). The data are expressed as means \pm SD. Differences were compared for statistical significance at the $p$-level less than $0.05(P<0.05)$

\section{RESULTS AND DISCUSSION}

The effect of short-term amygdalin administration on the serum levels of glucose

Serum levels of glucose after short-term IM injection of amygdalin to adult male rabbits were assessed in this in vivo study (Figure 1). During 28 days treatmen period, no significant $(P \geq 0.05)$ differences in serum levels of glucose were observed when compared to the untreated control group.

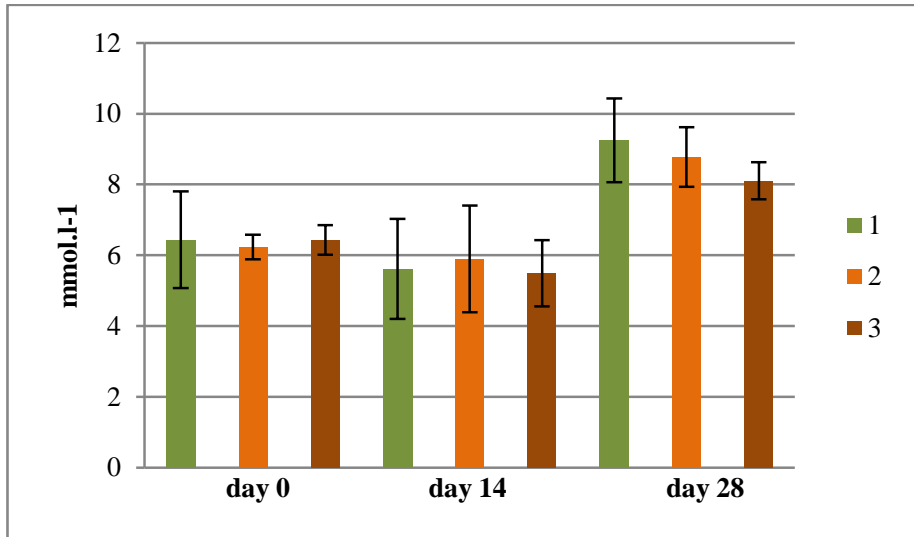

Figure 1 Serum levels of glucose during 28 days. 1 - control group (without amygdalin administration); 2 - group P1 $(0.6 \mathrm{mg} / \mathrm{kg}) ; 3$ - group P2 (3.0 mg/kg)

All the measured values of serum glucose were compared to reference range 4.1 - 8.5 mmol. . $^{-1}$ (Merck Sharp \& Dohme Corp., 2012). Two groups did not comply this range - control group $\left.\left(9.25 \mathrm{mmol}^{-1}\right)^{-1}\right)$ and $\mathrm{P} 1$ group $\left(8.78 \mathrm{mmol.} \mathrm{l}^{-1}\right)$, both after 28 days of experiment. On the other hand, Özkan et al. (2012) indicate there are some differences in reference ranges between male (3.83-10.77 mmol.1 $\left.{ }^{1}\right)$ and female (4.94-8.32 mmol. $\left.{ }^{-1}\right)$ rabbits. It has been reported that increased glucose levels in rabbits are generally due to various stress factors (Melillo, 2007; Jenkins, 2008).

The effect of short-term amygdalin administration on the plasma levels of triglycerides

Changes of triglycerides levels in response to amygdalin application were determined in this study as well. The effect of IM amygdalin aplication on rabbit serum levels of triglycerides is shown in Figure 2. The analysis has shown that the serum triglycerides levels of animals administered with 0.6 and $3.0 \mathrm{mg} / \mathrm{b}$.w. amygdalin did not statistically $(P \geq 0.05)$ differ, when compared to the control group.

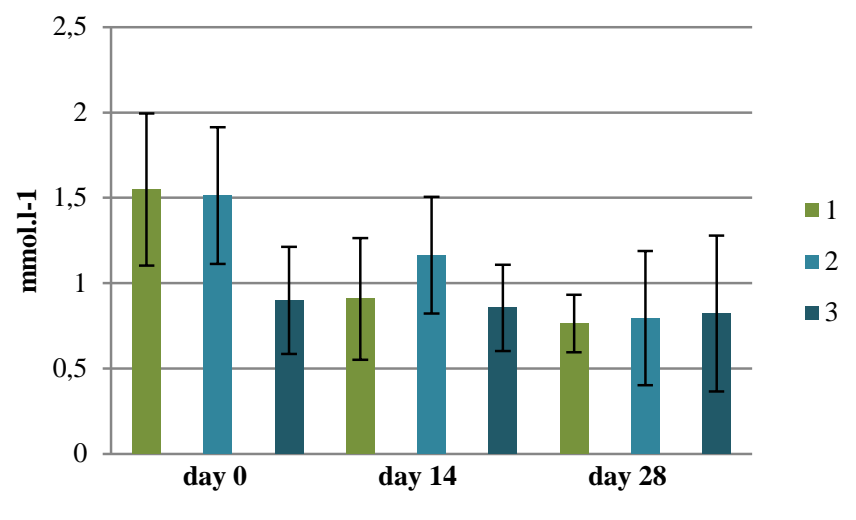

Figure 2 Serum levels of triglycerides during 28 days.

1 - control group (without amygdalin administration); 2 - group P1 (0.6 mg/kg); 3- group P2 $(3.0 \mathrm{mg} / \mathrm{kg})$

However, a non-significant decrease of triglycerides levels in all groups during the experiment was observed. It could be connected to slightly increased concentration of glucose, since the secretion of triglycerides serves as an additional potential energy source in the form of circulating lipids (Tuvdendor et al., 2015).

The effect of short-term amygdalin administration on the plasma levels of cholesterol

Serum levels of cholesterol after short-term IM injection of amygdalin to adult male rabbits were assessed and are shown in Figure 3. During 28 days of experiment, no significant $(P \geq 0.05)$ differences in serum levels of cholesterol were observed when compared to the untreated control group.

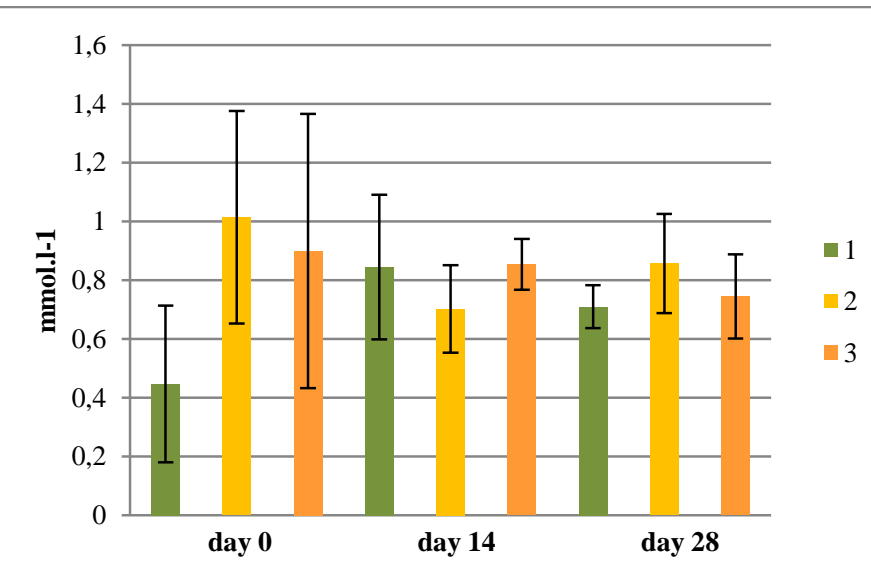

Figure 3 Serum levels of cholesterol during 28 days. 1 - control group (without amygdalin administration); 2 - group P1 (0.6 mg/kg); 3- group P2 (3.0 mg/kg)

Cholesterol molecule plays an important role in organism, e. g. in incorporation to cell membranes, or as precursor of steroid hormones (Vasudevan et al., 2011). Accorrding to veterinary manual of Merck Sharp \& Dohme Corp. (2012) levels of serum cholesterol of all groups were not outside the reference range (0.3-2.1 mmol. $\left.1^{-1}\right)$ and no significant differences between the groups were noticed during our experiment. These results could partly explain possible modulatory impact of amygdalin on the steroid production in porcine ovaries in vitro, as Halenár et al. (2015a, 2015b) published in their study. Keishi-bukuryo-gan (a traditional Chinese herbal remedy containing seeds of Prunus persica or P. persiba) and its crude ingredients affected steroidogenesis in pre-ovulatory follicles (Usuki, 1990,1991 ) in the rat ovary in vivo and in vitro.

There are just a few studies of blood chemistry changes after amygdalin administration in vivo. Similarly to our results, Miller et al. (1981) did not observe changes in blood chemistry of rats fed a diet containing $10 \%$ ground apricot kernels.

Our results showed some non-significant differences within the same groups between each blood collections. It is hypothesised that this difference may be due to the variations in some factors such as stress, blood collection methods and housing conditions (Özkan et al., 2012).

\section{CONCLUSION}

It can be summarized, that amygdalin had no significant effect (negative or beneficial) on energetic profile of male rabbits in this in vivo study. Our results 
showed some non-significant differences within the same groups between each blood collections, which may occur due to the variations in some factors such as stress, blood collection methods and housing conditions.

Acknowledgments: This work was financially supported by the Ministry of Education, Science, Research and Sport of the Slovak Republic projects no. 1/0022/13, APVV-0304-12, and European Community under project no 26220220180: Building Research Centre „AgroBioTech".

\section{REFERENCES}

BADR, J.M., TAWFIK, M.K. (2010). Analytical and pharmacologica investigation of amygdalin in Prunus armeniaca L. kernels. In Journal of Current Pharmaceutical Research, 3, 2134-2137.

BALMER, C. B. (1998). Alternative therapies in cancer patient care. In Highlights in oncology practice, 15, 83-84.

CHANG, H.K., SHIN, M.S., YANG, H.Y., LEE, J.W., KIM, Y.S., LEE, M.H. KIM, J., KIM, K.H., KIM, C.J. (2006). Amygdalin Induces Apoptosis through Regulation of Bax and Bcl-2 Expressions in Human DU145 and LNCaP Prostate Cancer Cells. In Biological and Pharmaceutical Bulletin, 29, 1597-1602. http://dx.doi.org/10.1248/bpb.29.1597

CHWALEK, M., PLE, K. (2004). Convenient syntheses of isomaltose derivatives from amygdalin. In Tetrahedron Letters, 45, 4749-4753. http://dx.doi.org/10.1016/j.tetlet.2004.04.057

FUKUDA, T., ITO, H., MUKAINAKA, T., TOKUDA, H., NISHINO, H. YOSHIDA, T. (2003). Anti-tumor promoting effect of glycosides from Prunus persica seeds. In Biological and Pharmaceutical Bulletin, 26, 271-273.

HALENÁR, M., MEDVEDOVÁ, M., MARUNIAKOVÁ, N., KOLESÁROVÁ, A. (2015a). Ovarian hormone production affected by amygdalin addition in vitro In Journal of Microbiology, Biotechnology and Food Sciences, 4, 19-22. http://dx.doi.org/10.15414/jmbfs.2015.4.special2.19-22

HALENAR, M., MEDVEDOVA,M., MARUNIAKOVA, KOLESAROVA, A (2015b). Assessment of a potential preventive ability of amygdalin in mycotoxininduced ovarian toxicity. In Journal of Environmental Science and Health B 50(6), 411-416. http://dx.doi.org/10.1080/03601234.2015.1011956

JENKINS, J. R. (2008). Rabbit diagnostic testing. In Journal of Exotic Pet Medicine, 17, 4-15. http://dx.doi.org/10.1053/j.jepm.2007.12.003

LEVI, L., FRENCH, W. N., BICKIS, I. J., HENDERSON, I. W. D. (1965).

Laetrile: A Study of Its Physicochemical and Biochemical Properties. In Canadian Medical Association Journal, 92 (20), 1057-1061.

LV, W.F., DING, M. Y., ZHENG, R. (2005). Isolation and quantitation of amygdalin in apricot kernel and Prunus Tomentosa Thunb. by HPLC with solid phase extraction. In Journal of Chromatographic Science, 43, 383-387. http://dx.doi.org/10.1093/chromsci/43.7.383

MERCK SHARP \& DOHME CORP. (2012). Serum Biochemical Reference Ranges. The Merck Veterinary Manual [online], [cit. 2015-10-30]. Available on internet:

http://www.merckmanuals.com/vet/appendixes/reference guides/serum biochem ical_reference_ranges.html

MELILLO, A. (2007). Rabbit clinical pathology. In Journal of Exotic Pet Medicine, 16, 135-145. http://dx.doi.org/10.1053/j.jepm.2007.06.002

MILLER, K. W., ANDERSON, J. L., STOEWSAND, G. S. (1981). Amygdalin metabolism and effect on reproduction of rats fed apricot kernels. In Journal of Toxicology and Environmental Health, 7, 457-467. http://dx.doi.org/10.1080/15287398109529994

ÖZKAN, C., KAYA, A., AKGÜL Y. (2012). Normal values of haematological and some biochemical parameters in serum and urine of New Zealand White $\begin{array}{llll}\text { rabbits. In } \quad \text { World } & \text { 253-259. }\end{array}$ http://dx.doi.org/10.4995/wrs.2012.1229

SOLLMANN, T. (1949). Manual of Pharmacology (7th edition). London and Philadelphia: W. B. Saunders Company.

SONG, Z., XU, X. (2014). Advanced research on anti-tumor effects of amygdalin. In Journal of Cancer Resesarch \& Therapy, 1, 3-7. http://dx.doi.org/10.4103/0973-1482.139743

TUVDENDORJ, D., ZHANG, X., CHINKES, D. L., WANG, L., WU, Z., RODRIGUEZ, N. A., HERNDON, D. N., WOLFE, R. R. (2015). Triglycerides produced in the livers of fasting rabbits are predominantly stored as opposed to secreted into the plasma. In Metabolism, 64, 580-587. http://dx.doi.org/10.1016/j.metabol.2015.01.002

USUKI, S. (1990). Effects of Tokishakuyakusan and Keishibukuryogan on steroidogenesis by rat preovulatory follicles in vivo. In American Journal of Chinese Medicine, 18, 149-156. http://dx.doi.org/10.1142/S0192415X90000198

USUKI, S. (1991). Effects of Hachimijiogan, Tokishakuyakusan and Keishibukuryogan, Ninjinto and Unkeito on estrogen and progesterone secretion in preovulatory follicles incubated in vitro. In American Journal of Chinese Medicine, 19, 65-71. http://dx.doi.org/10.1142/S0192415X91000107

VASUDEVAN, D. M., SREEKUMARI, S., VAIDYANATHAN, K. (2011).

Textbook of Biochemistry for Medical Students, 6th edition. New Delhi: Jaypee Brothers Medical Publishers. 2011.
ZHOU, C., QIAN, L., MA, H., YU, X., ZHANG, Y., QU, W., ZHANG, X., XIA W. (2012). Enhancement of amygdalin activated with $\beta$-D-glucosidase on HepG2 cells proliferation and apoptosis. In Carbohydrate Polymers, 90, 516-523. http://dx.doi.org/10.1016/j.carbpol.2012.05.073 